Erik Esche, Harvey Arellano-Garcia, Lorenz T. Biegler

\title{
Optimal operation of a membrane reactor network
}

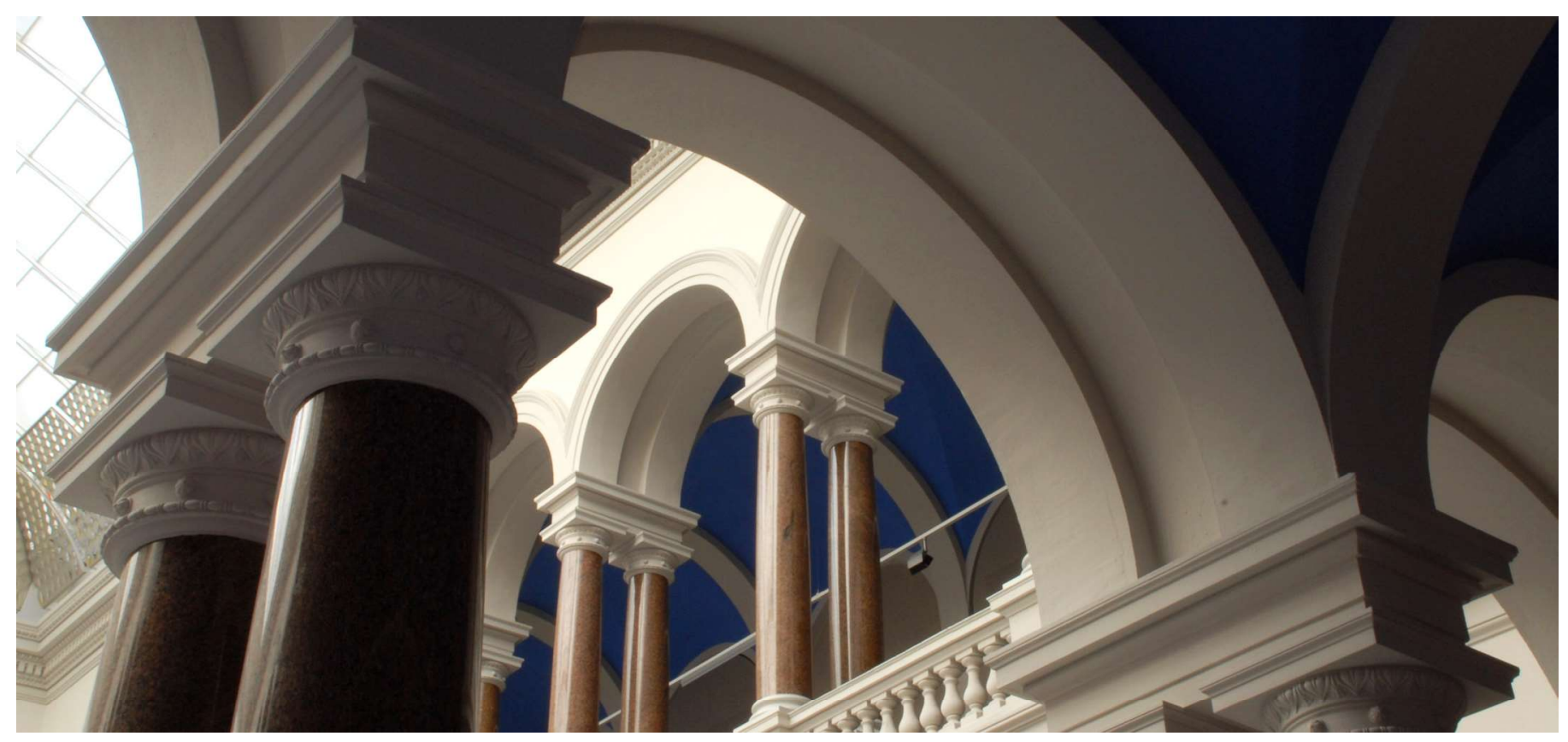

This is the peer reviewed version of the following article:

Esche, E., Arellano-Garcia, H. \& Biegler, L. T. (2013). Optimal operation of a membrane reactor network. AIChE Journal, 60(1), 170-180. https://doi.org/10.1002/aic.14252,

which has been published in final form at https://doi.org/10.1002/aic.14252. This article may be used for non-commercial purposes in accordance with Wiley Terms and Conditions for Use of Self-Archived Versions. 


\title{
Optimal Operation of a Membrane Reactor Network
}

\author{
Erik Esche ${ }^{*, \dagger}$ Harvey Arellano-Garcia, ${ }^{\dagger}$ and Lorenz T. Biegler ${ }^{\dagger}$ \\ Chair of Process Dynamics and Operation, Berlin University of Technology, Sekr. KWT-9, Str. des \\ 17. Juni 135, D-10623 Berlin, Germany, and Department of Chemical Engineering, Carnegie \\ Mellon University, 5000 Forbes Avenue, Pittsburgh, PA 15213, USA \\ E-mail: erik.esche@tu-berlin.de
}

\section{In honor of Günter Wozny's 65th birthday}

\begin{abstract}
In this work, a two-dimensional model for a conventional packed-bed membrane reactor $(C P B M R)$ is presented. The model incorporates radial diffusion and thermal conduction. In addition, two $10 \mathrm{~cm}$ long cooling segments for the $C P B M R$ were implemented based on the idea of a fixed cooling temperature positioned outside the reactor shell. The model is discretized using two-dimensional orthogonal collocation on finite elements with a combination of Hermite for the radial and Lagrangian polynomials for the axial coordinate. Membrane thickness, feed compositions, temperatures at the inlet and for the cooling, diameters, and the amount of inert packing in the reactor are considered as decision variables. The optimization results in $C_{2}$ yields of up to $40 \%$ with a selectivity in $C_{2}$ products of more than $60 \%$. In addition, the $C P B M R$ model is integrated into a membrane reactor network (MRN) consisting of an additional packed-bed membrane reactor with an alternative feeding policy and a fixed-bed reactor.
\end{abstract}

Keywords: OCM, Membrane Reactor Network, Orthogonal Collocation, large-scale NLP

\footnotetext{
${ }^{*}$ To whom correspondence should be addressed

${ }^{\dagger}$ Berlin

†Pittsburgh
} 


\section{Motivation and Introduction}

For remote, isolated wells of natural gas, a combination of steam reforming and Fischer-Tropsch synthesis is often applied to turn methane into more easily transportable and chemically processable hydrocarbons. However, this process demands enormous amounts of energy and has an efficiency between 25 and $50 \%$ depending on reactant compositions and operating conditions. ${ }^{1}$ An alternative to this process is the oxidative coupling of methane $(O C M)$, which has the potential to become a key technology in chemical industry. ${ }^{2}$ The $O C M$ process allows for direct production of alkenes (olefins) or alkanes from methane $\left(\mathrm{CH}_{4}\right)$. It skips the energy intensive syngas formation (steam reforming) and could thus potentially be more energetically and economically efficient. This process offers various opportunities for replacing oil with natural gas.

As part of the Cluster of Excellence "Unifying Concepts in Catalysis" (UniCat) a a mini-plant is being built at the Berlin Institute of Technology (Technische Universität Berlin) to investigate the technical viability of the OCM process on a larger scale. This contribution deals with the modelling and optimization of a part of that mini-plant, namely, a membrane reactor network.

Forthwith, the $\mathrm{La}_{2} \mathrm{O}_{3} / \mathrm{CaO}$-catalyst is employed for OCM. Given the exothermic nature of OCM and the undesired simultaneous creation of carbon oxides, any practical application should allow for good temperature control and low oxygen levels. Several apparatuses like fluidized bed reactors and fixed-bed reactors $(F B R$ s) have been tested therefore, where pellets in the bed carry the required catalyst. In a classical $F B R$, the equilibrium composition can ideally be attained at the outlet and the product streams need to be further processed to extract ethylene and other hydrocarbons. A more promising approach has been developed by Lafarga et al. in the form of packed-bed membrane reactors $(P B M R \mathrm{~s})$, which offer additional benefits by gradually feeding oxygen to the catalyst so as to allow for a higher selectivity in $C_{2}$ products, meaning lower carbon oxide formation. ${ }^{3} P B M R$ s are comparatively simple in their process design, and safer in operation than an FBR. ${ }^{5}$ They not only offer enhanced catalytic activity and selectivity, but also include the product separation.

\footnotetext{
${ }^{\mathrm{a}}$ For further information on UniCat visit http: //www . unicat.tu-berlin.de.
} 
Nevertheless, a permeable membrane implies loss of reactants by diffusion to the non-catalytic side of the reactor. One measure, which reduces this effect, is the introduction of a recycle stream feeding a part of a product stream back into the system. ${ }^{7} 1$ shows the membrane reactor network $(M R N)$ proposed by Godini et al. ${ }^{8}$

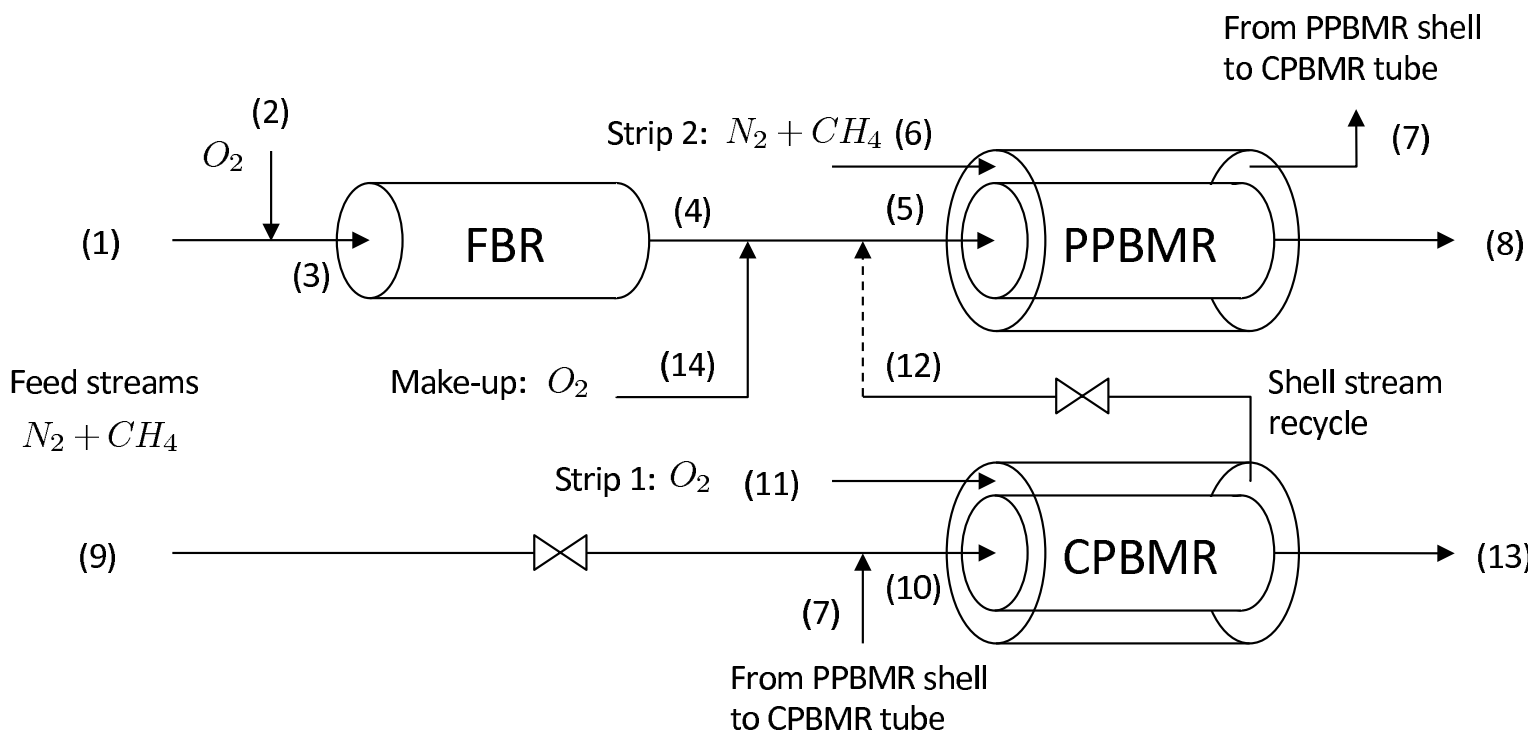

Figure 1: Flowsheet of the proposed membrane reactor network. Figure redrawn in accordance with. ${ }^{8}$

The network consists of three different types of reactors: a common fixed-bed $(F B R)$ or plug flow reactor $(P F R)$, a conventional packed-bed membrane reactor $(C P B M R)$ and an alternative, proposed packed-bed membrane reactor $(P P B M R) .{ }^{8}$

The foremost aim of this contribution is not to discuss the optimal structure of a membrane reactor network for the $O C M$ process, but to model and optimize the operation of the given network.

In previously conducted work by Jašo and Godini et al. , only one-dimensional models for the three afore-mentioned reactors were applied to investigate the attainable reactor performance. ${ }^{29}$ Their investigations of the reactor performance included the influence of operating temperature, membrane thickness, methane-to-oxygen ratio at the reactor inlet, overall feed flow rates, gas stream compositions, and reactor lengths. They saw the temperature rising especially in the $F B R$ by more than $500 \mathrm{~K}$ despite cooling the reactor through its outer shell. Godini et al. proposed the afore- 
mentioned feeding policy for the given membrane reactor network. ${ }^{8}$ Their strategy of running a fixed-bed reactor and a conventional packed-bed membrane reactor alongside each other and connecting them both through a proposed packed-bed membrane reactor and recycles allows for an increase in both yield and selectivity. They started with separate studies of all three reactors by implementing one-dimensional stationary models to test the effect of oxygen accessibility. The PPBMR differs from the CPBMR only insofar as methane and oxygen are co-fed to the packedbed (tube-side) of the reactor. This new feeding strategy allows for the above-mentioned network improvements. Their analyses showed an overall yield in $C_{2}$ products of $23.21 \%$, a $C_{2}$ selectivity of $53.93 \%$, and a methane conversion of $42.66 \%$.

The following chapters present a brief overview on how all three reactors are modeled before discussing the simulation and optimization of the membrane reactor network.

\section{Derivation of Models}

In order to model and optimize the whole network, a model for each of the reactors has been developed. This section introduces models for all three reactors and outlines how source terms and transport coefficients are calculated. Moreover, a collocation method for a set of partial differential equations is discussed.

One- and Two-Dimensional Models: Previously implemented one-dimensional models have shown higher yields in $C_{2}$ hydrocarbons than physically possible, the focus of this contribution lies on two-dimensional modelling. The CPBMR is expected to have the largest impact on the behaviour of the whole network by far. Therefore, a two-dimensional model is implemented for the CPBMR and one-dimensional models are considered for the other two reactors. All symbols stated in the following equations are noted and explained in the nomenclature. The one-dimensional model for the FBR consists of the following differential equations describing concentration and 
temperature profiles:

$$
\begin{gathered}
\frac{\partial c_{i}}{\partial z}=\frac{\dot{c} r_{i}}{u_{z}} \\
\frac{\partial T}{\partial z}=\frac{-k_{O S} \cdot\left(T(z)-T_{\mathrm{cool}}\right) \cdot 2+\sum_{j=1}^{N R}\left(\varphi_{\mathrm{cat}} \cdot \rho_{\mathrm{cat}} \cdot \dot{r} r_{j} \cdot\left(-\Delta_{R} H\right)\right) \cdot r_{F B R}}{c_{\mathrm{tot}} \cdot c_{p, \operatorname{mix}} \cdot u_{z} \cdot r_{F B R}}
\end{gathered}
$$

The reactor is heated or cooled through its lateral, outer shell. $T_{\text {cool }}$ is the temperature of the cooling jacket and $k_{O S}$ the respective heat transfer coefficient.

For the PPBMR the influence of the membrane and the shell-side of the reactor need to be added to the set of differential equations. Consequently, each side has its own equations for concentrations and temperatures as follows:

$$
\begin{aligned}
& u_{z, T} \cdot \pi \cdot r_{\text {tube }}^{2} \frac{\partial c_{i, \text { tube }}}{\partial z} \cdot d z=\dot{c} r_{i} \cdot \pi \cdot r_{\text {tube }}^{2} \cdot d z-d \dot{N}_{i, \operatorname{diff}}(z) \\
& u_{z, S} \cdot \pi \cdot\left(r_{\text {shell }}^{2}-r_{\text {tube }}^{2}\right) \cdot \frac{\partial c_{i, \text { shell }}}{\partial z} \cdot d z=d \dot{N}_{i, \text { diff }}(z) \\
& \frac{\partial T^{T}}{\partial z}=\frac{\sum_{j=1}^{N R}\left(\varphi_{\text {cat }} \cdot \rho_{\text {cat }} \cdot \dot{r} r_{j} \cdot\left(-\Delta_{R} H\right)\right) \cdot \pi \cdot r_{T}^{2}}{c_{\text {tot }}^{T} \cdot c_{p, \text { mix }}^{T} \cdot u_{z}^{T} \cdot \pi \cdot r_{T}^{2}} \\
& -\frac{\dot{h}_{\mathrm{diff}} \cdot 2 \cdot \pi \cdot r_{S}}{c_{\mathrm{tot}}^{T} \cdot c_{p, \text { mix }}^{T} \cdot u_{z}^{T} \cdot \pi \cdot r_{T}^{2}}-\frac{\dot{q}_{\mathrm{trans}} \cdot 2 \cdot \pi \cdot r_{S}}{c_{\mathrm{tot}}^{T} \cdot c_{p, \text { mix }}^{T} \cdot u_{z}^{T} \cdot \pi \cdot r_{T}^{2}} \\
& \frac{\partial T^{S}}{\partial z}=\frac{\dot{h}_{\mathrm{diff}} \cdot 2 \cdot \pi \cdot r_{S}}{c_{\mathrm{tot}}^{S} \cdot c_{p, \text { mix }}^{S} \cdot u_{z}^{S} \cdot \pi \cdot\left(r_{S}^{2}-r_{T}^{2}\right)}+\frac{\dot{q}_{\mathrm{trans}} \cdot 2 \cdot \pi \cdot r_{S}}{c_{\mathrm{tot}}^{S} \cdot c_{p, \text { mix }}^{S} \cdot u_{z}^{S} \cdot \pi \cdot\left(r_{S}^{2}-r_{T}^{2}\right)} \\
& -\frac{k_{O S} \cdot\left(T^{S}(z)-T_{\mathrm{cool}}\right) \cdot 2 \cdot \pi \cdot r_{S}}{c_{\mathrm{tot}}^{S} \cdot c_{p, \text { mix }}^{S} \cdot u_{z}^{S} \cdot \pi \cdot\left(r_{S}^{2}-r_{T}^{2}\right)}
\end{aligned}
$$

2(a) and 2(b) show a sketch of the CPBMR and a differential volume element of its tube-side, 
respectively. Hence, the mass balance for the tube-side leads to:

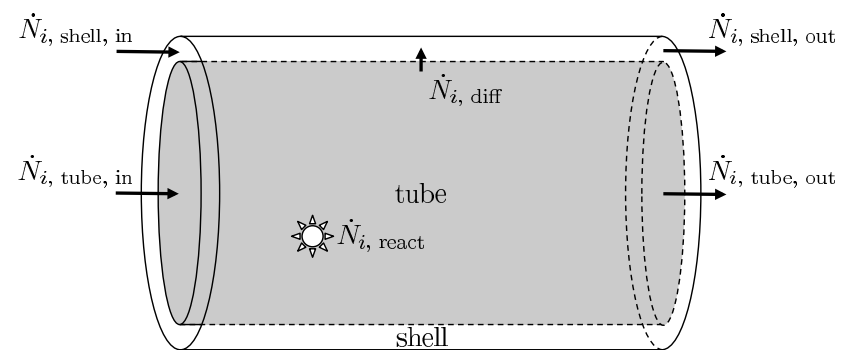

(a) Sketch of the CPBMR for the isothermal model.

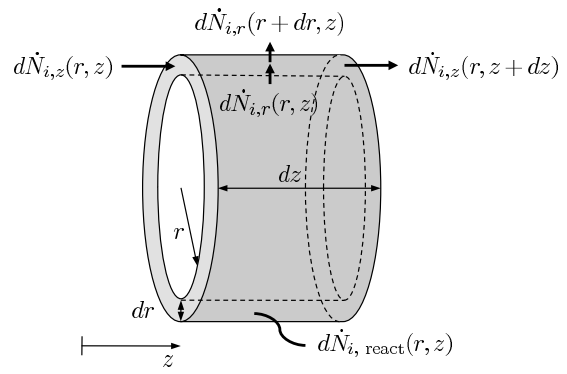

(b) Differential segment of the tube-side of the $C P B M R$ for the isothermal model.

Figure 2: Balance volume for the derivation of the isothermal model for the CPBMR.

$$
0=-u_{z} \cdot \frac{\partial c_{i}(r, z)}{\partial z}+\mathscr{D}_{i, r} \cdot\left[\frac{\partial^{2} c_{i}}{\partial r^{2}}+\frac{1}{r} \cdot \frac{\partial c_{i}}{\partial r}\right]+\dot{c} r_{i}
$$

and for the shell-side respectively:

$$
0=-u_{z} \cdot \frac{\partial c_{i}(r, z)}{\partial z}+\mathscr{D}_{i, r} \cdot\left[\frac{\partial^{2} c_{i}}{\partial r^{2}}+\frac{1}{r} \cdot \frac{\partial c_{i}}{\partial r}\right]
$$

The two-dimensional modelling moves the equations for the heat transfer through the outer shell and the membrane to the boundary conditions. A differential energy balance of the tube-side of the CPBMR leads to:

$$
c_{\mathrm{tot}} \cdot c_{p, \text { tot }} \cdot u_{z} \cdot \frac{\partial T}{\partial z}=\lambda \cdot\left[\frac{\partial^{2} T}{\partial r^{2}}+\frac{1}{r} \cdot \frac{\partial T}{\partial r}\right]+\sum_{j=1}^{N R}\left(\varphi_{\text {cat }} \cdot \rho_{\text {cat }} \cdot \dot{r} r_{j} \cdot\left(-\Delta_{R} H\right)\right)
$$

For the description of the shell-side, the reaction term simply needs to be left out:

$$
c_{\mathrm{tot}} \cdot c_{p, \text { tot }} \cdot u_{z} \cdot \frac{\partial T}{\partial z}=\lambda \cdot\left[\frac{\partial^{2} T}{\partial r^{2}}+\frac{1}{r} \cdot \frac{\partial T}{\partial r}\right]
$$

3 shows the basic idea of the heated or cooled model for the CPBMR. Each $10 \mathrm{~cm}$ segment of the 


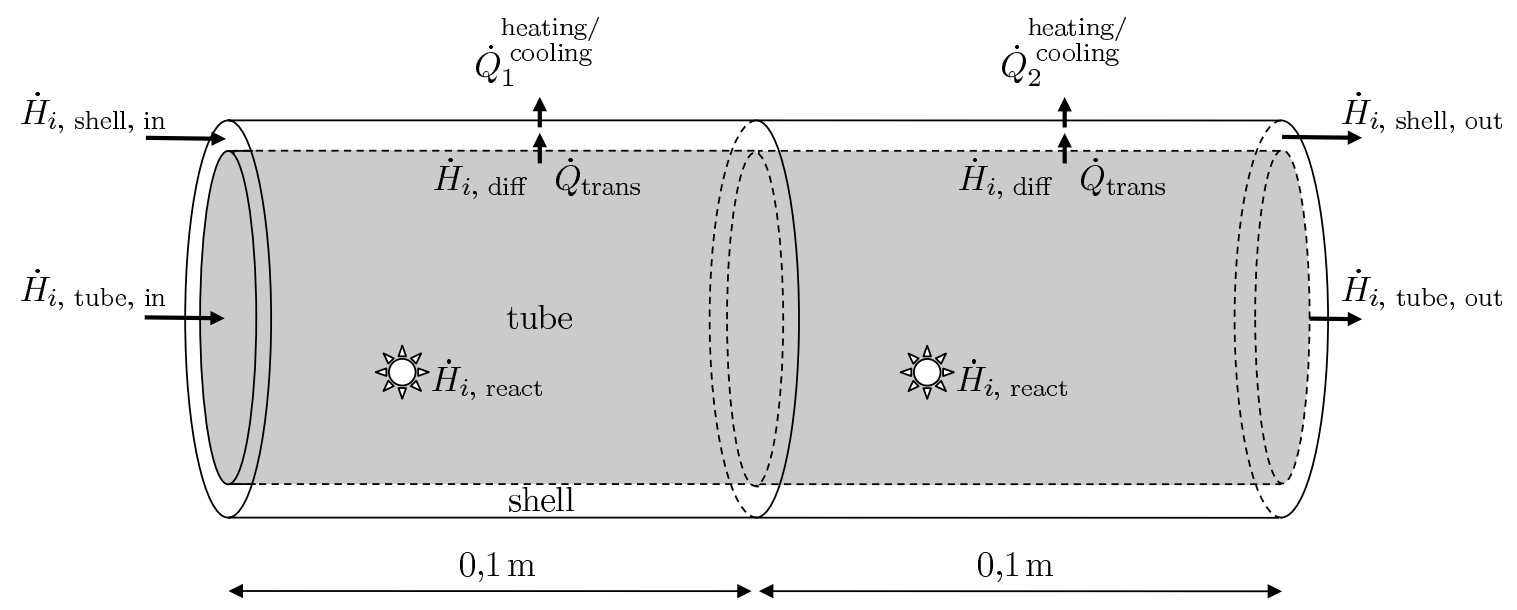

Figure 3: Sketch for the heated or cooled model of the CPBMR.

reactor can be cooled or heated separately through the outer shell according to:

$$
\begin{aligned}
\dot{q}_{\text {heat } / \text { cool }}(z) & =k_{\mathrm{OS}} \cdot\left(\left.T\left(r=r_{\text {shell }}, z\right)\right|_{\text {shell }}-T_{\text {cool }}\right) \\
& =-\left.\lambda_{\text {mix }}^{G}\left(r=r_{\text {shell }}, z\right) \cdot \frac{\partial T}{\partial r}\right|_{\text {shell }}
\end{aligned}
$$

Fluid Properties, Transport Parameters, and Reaction Kinetics: All gases are assumed to behave as perfect or ideal gases. Correlations published in ${ }^{10}$ are employed to calculate viscosities, thermal conductivities of pure components, etc.

The shell of the CPBMR is void of any internal installations. Hence, it can be assumed that the radial flux in the shell is due to common gas diffusion. Fuller et al. present a semi-theoretical, semi-empirical function for the calculation of binary diffusion coefficients. ${ }^{11}$ Using these binary diffusion coefficients, Kee et al. introduced mixture averaged diffusion coefficients, which are applied as diffusion coefficients for the shell-side of the CPBMR. ${ }^{13}$ The packed-bed in the tube of the CPBMR impedes the diffusion of gas and the axial flow through the packed-bed of course affects the radial mass transport. In this contribution, an approach suggested by Tsotsas and Schlünder et al. is used, which has already been successfully applied to a packed-bed membrane reactor, in which a radial effective dispersion coefficient is defined for each component as the sum of a molecular and a crossmixing term, where the molecular term may be calculated in accordance with Kee 
et al.'s correlation. ${ }^{1416}$

In this work, a porous membrane, which allows the permeation of gas, separates shell- and tubeside of the CPBMR. The flux of any component through the membrane is calculated with the help of Kundsen's diffusivity theory as has been experimentally shown by Lafarga et al. ${ }^{17}$ Diffusion is assumed to be the only radial transport mechanism. Therefore, the flux through the membrane of a component $i$ on either side can also be described with Fick's law.

For the thermal conductivity of the gas mixture in the shell-side, a model presented in ${ }^{18}$ may be used. To combine individual thermal conductivities into a single one for the whole mixture, the rule developed by Wassiljeva, Mason, and Saxena ${ }^{19}$ is applied. Several approaches exist, which describe the effective radial thermal conductivity $\lambda_{\text {eff }}$ in a packed-bed. A model for the radial thermal conduction published by Bauer and Schlünder ${ }^{2021}$ is employed.

Two different types of transport cause a heat flux through the membrane separating shell- and tube-side of the CPBMR: The diffusive mass transport brings about an enthalpy flow $\dot{h}_{\text {membrane }}$ and conduction of the membrane itself enables heat transfer $\dot{q}_{\text {membrane }}$ between both sides:

$$
\begin{aligned}
& \dot{q}_{\text {membrane }}=k_{\text {membrane }} \cdot\left(T_{\text {tube }}\left(r=r_{\text {tube }}, z\right)-T_{\text {shell }}\left(r=r_{\text {tube }}, z\right)\right) \\
& \dot{h}_{\text {membrane }}=\sum_{i=1}^{N C}\left(\dot{n}_{i, \text { diff }} \cdot c_{p, i}\right) \cdot\left(T_{\text {tube }}\left(r=r_{\text {tube }}, z\right)-T_{\text {shell }}\left(r=r_{\text {tube }}, z\right)\right)
\end{aligned}
$$

Specchia et al. ${ }^{22}$ published correlations for the calculation of heat transfer coefficients for heat transfer through walls adjoining catalytic packed-beds. For the one-dimensional case, a different approach is required as there are no temperature gradients on either side of the membrane. Dixon ${ }^{23}$ developed correlations for the latter case. Moreover, the kinetic model of Stansch et al. for the oxidative coupling of methane over a $\mathrm{La}_{2} \mathrm{O}_{3} / \mathrm{CaO}$-catalyst is used in this work. Their reaction mechanism is detailed in. ${ }^{24}$

Orthogonal Collocation for Reactor Models: All differential equations in this contribution are discretized via orthogonal collocation on finite elements. Third order Lagrangian polynomials are 
employed to collocate ODEs (ordinary differential equations) on finite elements using Radau roots to guarantee the continuity of each variable across finite elements. ${ }^{26}$

For partial differential equations (PDEs) a combination of Hermite and Lagrangian polynomials is derived for the descretization. In case second order derivatives appear in a differential equation, the continuity of first order derivatives across finite elements needs to be ensured. For this application, Hermite cubic polynomials are of advantage. Their usage guarantees the continuity of the function itself and its first derivative between two adjoining finite elements. The polynomials employed forthwith are taken from Finlayson, who used Hermite polynomials for the two-dimensional discretization of a sphere. ${ }^{28}$

The basic idea of extending the one-dimensional orthogonal collocation to a second dimension is to use different functions for each direction, which depend on different variables and then multiply both of them.

$$
c_{L H}(u, v)=\left(\sum_{l=1}^{4} a_{u, l} \cdot \ell_{l}(u)\right) \cdot\left(\sum_{l=1}^{4} a_{v, l} \cdot \mathscr{H}_{l}(v)\right)
$$

Equation 15 can also be written as follows where $a_{i, j}=a_{u, i} \cdot a_{v, j}$ :

$$
\begin{aligned}
c_{L H}(u, v) & =a_{1,1} \cdot \ell_{1}(u) \cdot \mathscr{H}_{1}(v)+a_{1,2} \cdot \ell_{1}(u) \cdot \mathscr{H}_{2}(v)+a_{1,3} \cdot \ell_{1}(u) \cdot \mathscr{H}_{3}(v) \\
& +a_{1,4} \cdot \ell_{1}(u) \cdot \mathscr{H}_{4}(v)+a_{2,1} \cdot \ell_{2}(u) \cdot \mathscr{H}_{1}(v)+\ldots+a_{4,4} \cdot \ell_{4}(u) \cdot \mathscr{H}_{4}(v)
\end{aligned}
$$

The new approximation function, which is basically a surface function, contains 16 coefficients $a_{i, j}$, half of which assume the value of the collocated variable at certain collocation positions and the other half are the respective first, radial derivative. This is depicted in 4.

Application of Orthogonal Collocation to Reactor Models: The two-dimensional model for the $C P B M R$ is discretized using orthogonal collocation as described above. Hence, the $C P B M R$ displayed in 2(a) needs to be divided into several axial and radial finite elements. The following scheme is applied to formulate a linearly independent set of equations based on the discretized differential equations: The assessment of each stand-alone reactor and the network is done using 


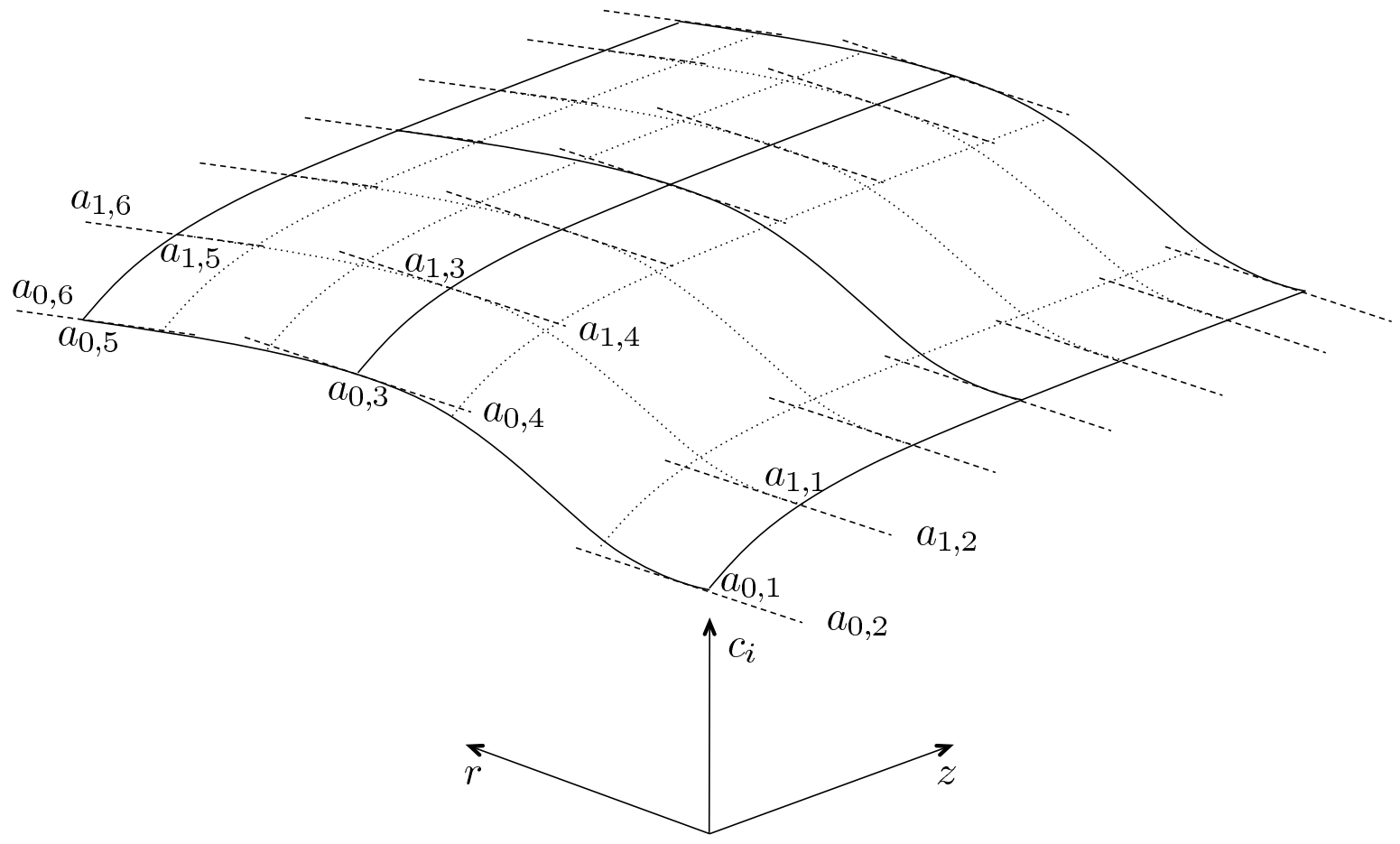

Figure 4: Depiction of the collocating surface function using Hermite and Lagrangian polynomials and the meaning of respective collocation variables.

Godini et al.'s ${ }^{8}$ definitions of yield $Y$, selectivity $S$ in $C_{2}$ hydrocarbons, and $\mathrm{CH}_{4}$ conversion $\mathrm{X}$. In order to solve the resuling NLP problem, the interior point barrier method implemented in IPOPT is used. For details see Biegler et al. ${ }^{29} 30$

\section{Stand-Alone Operation of the CPBMR}

Preceding the optimization, extensive simulation studies are carried out. To accurately simulate the CPBMR, three radial finite elements for the tube-side, two for the shell-side, and twelve axial finite elements are required. By making each of the aforementioned model parameters in turn dependent on local concentrations and temperatures, it could be found that all fluid properties and transport coefficients should in fact not be calculated with averaged concentrations and temperatures, but using locally dependent values. Relative errors of mass and atom balances are below $10^{-5}$. Ignoring the heat of reaction or the influence of the heat loss through the outer shell can have a big impact on 
the performance. Non-isothermal models should be preferred at all times. A comparison between the two-dimensional and a one-dimensional model shows an overestimation of the reactor performance in terms of yield in $C_{2}$ hydrocarbons by as many as 25 percentage points. The full-scale model for the CPBMR consists of around 160000 variables. Due to the reaction kinetics and some of the correlations for transport parameters, the entire system is highly non-linear. Consequently, a number of measures is tested to improve the convergence behaviour of the entire system such as avoiding non-differentiable points, scaling of variables (e.g. using natural logarithms), linearising constraints, increasing the sparsity of matrices, and tuning IPOPT. While the manual scaling did not yield any actual improvements, especially as there are no practical ways to scale second order derivatives, tuning IPOPT led to some measurable reductions of the convergence time. By choosing MA57 from the Harwell Subroutine Library ${ }^{31}$ as a linear solver and the Metis package for matrix reordering, ${ }^{32}$ the convergence time could be reduced to less than $25 \%$ in comparison to the default configuration.

Optimization of the CPBMR: Several operational and geometrical parameters of the CPBMR can be manipulated. The following 1 contains a comprehensive list of parameters of the $C P B M R$ that may be modified within given bounds. For matters of problem size, additional possible decision variables are disregarded. Among those are the inlet pressures for shell- and tube-side, superficial velocities, and selection of the right type of catalyst. Similarly, the reactor length will be held constant at $20 \mathrm{~cm}$, because of the difficulties related to removing or adding an entire heating/cooling segment, each of which is $10 \mathrm{~cm}$ long. The lower and upper bounds noted in 1 state what should be possible theoretically.

2 shows the configuration and the performance at the starting point (0), an intermediate step (1), and the final optimization results (2). $L$ and ${ }^{U}$ assign active lower or upper bounds on decision variables, which are specified by the user. Figure 5 shows the concentration profiles for ethylene and ethane and the temperature profile for the final optimization step noted in 2. 
Table 1: Operational and geometrical parameters of the $C P B M R$ that may be modified within the given bounds.

\begin{tabular}{|c|c|c|c|c|c|}
\hline Parameter & Symbol & Value & $\begin{array}{l}\text { Lower } \\
\text { bound }\end{array}$ & $\begin{array}{l}\text { Upper } \\
\text { bound }\end{array}$ & Unit \\
\hline \multicolumn{6}{|c|}{ Geometrical Parameters } \\
\hline Diameter of tube & $d_{\text {tube }}$ & 0.007 & $\overline{00}$ & $\bar{~} d_{\text {shell }}$ & $\mathrm{m}$ \\
\hline Diameter of shell & $d_{\text {shell }}$ & 0.010 & $d_{\text {tube }}$ & - & $\mathrm{m}$ \\
\hline Membrane thickness & $\delta_{\text {mem }}$ & 50 & 0.1 & 100 & $\mu \mathrm{m}$ \\
\hline Catalyst density & $\rho_{\text {cat }}$ & 3600 & 0 & 3700 & $\mathrm{~kg} / \mathrm{m}^{3}$ \\
\hline Catalyst volume fraction & $\varphi_{\text {cat }}$ & 0.64 & 0 & 1 & - \\
\hline \multicolumn{6}{|c|}{ Operational Parameters } \\
\hline Temperature at inlet, shell-side & $T_{\text {Inlet }}^{S}$ & 1023.15 & 290 & 1375 & $\mathrm{~K}$ \\
\hline Temperature at inlet, tube-side & $T_{\text {Inlet }}^{T}$ & 1023.15 & 290 & 1375 & $\mathrm{~K}$ \\
\hline Cooling/heating temperature, seg. I & $T_{h / c}^{I}$ & 1023.15 & 290 & 1375 & $\mathrm{~K}$ \\
\hline Cooling/heating temperature, seg. II & $T_{h / c}^{I I}$ & 1023.15 & 290 & 1375 & $\mathrm{~K}$ \\
\hline Molar fraction of oxygen, shell-side & $x_{O_{2}}$ & 0.128 & 0 & 1 & - \\
\hline Molar fraction of nitrogen, tube-side & $x_{C H_{4}}^{T^{2}}$ & 0.170 & 0 & 1 & - \\
\hline
\end{tabular}

Table 2: Collection of decision variables for three steps in the optimization of the CPBMR and respective performance.

\begin{tabular}{lrrrrrr}
\hline No. & $\begin{array}{r}T_{\mathrm{in}}^{\mathrm{S}} \\
{[\mathrm{K}]}\end{array}$ & $\begin{array}{r}T_{\mathrm{in}}^{\mathrm{T}} \\
{[\mathrm{K}]}\end{array}$ & $\begin{array}{r}T_{\mathrm{h} / \mathrm{c}}^{\mathrm{I}} \\
{[\mathrm{K}]}\end{array}$ & $\begin{array}{r}T_{\mathrm{h} / \mathrm{c}}^{\mathrm{II}} \\
{[\mathrm{K}]}\end{array}$ & $\begin{array}{r}x_{O_{2}}^{\mathrm{S}} \\
{[-]}\end{array}$ & $\begin{array}{r}x_{C H_{4}}^{\mathrm{T}} \\
{[-]}\end{array}$ \\
\hline \hline 0 & 1023 & 1023 & 1023 & 1023 & 0.128 & 0.170 \\
1 & $990_{L}$ & $990_{L}$ & $990_{L}$ & $990_{L}$ & $0.149^{U}$ & $0.162_{L}$ \\
2 & $970_{L}$ & 1013 & $970_{L}$ & $970_{L}$ & $0.157^{U}$ & 0.128 \\
\hline No. & $d_{\mathrm{T}}$ & $d_{\mathrm{S}}$ & $\rho_{\mathrm{cat}}$ & $\varphi_{\mathrm{cat}}$ & $\delta_{\mathrm{mem}}$ & \\
& {$[\mathrm{mm}]$} & {$[\mathrm{mm}]$} & {$\left[\mathrm{kg} / \mathrm{m}^{3}\right]$} & {$[-]$} & {$[\mu \mathrm{m}]$} & \\
\hline \hline 0 & 7.0 & 10 & 3600 & 0.64 & 50 & \\
1 & $6.0_{L}$ & $7.8_{L}$ & $3700^{U}$ & $0.70^{U}$ & 62.4 & \\
2 & $6.0_{L}$ & $7.8_{L}$ & $3700^{U}$ & $0.70^{U}$ & $65^{U}$ & \\
\hline
\end{tabular}

\begin{tabular}{lrrr}
\hline No. & $\begin{array}{r}\text { Yield } \\
\text { in } C_{2}\end{array}$ & $\begin{array}{r}\text { Selectivity } \\
\text { in } C_{2}\end{array}$ & $\begin{array}{r}\text { Conversion } \\
\text { of } \text { CH }_{4}\end{array}$ \\
\hline \hline 0 & 0.302983 & 0.550275 & 0.550604 \\
1 & 0.440726 & 0.685512 & 0.642914 \\
2 & 0.468500 & 0.632873 & 0.740276 \\
\hline
\end{tabular}

\section{Selectivity Target}

While having a high yield in $C_{2}$ products is advantageous, the product gas still needs to be cleaned of both reactants and side-products, like carbon ${ }_{12}$ xides, before further processing. The selectivity 
in $C_{2}$ hydrocarbons is a measure for how many of the reacted methane molecules formed hydrocarbons and how many carbon atoms went into the formation of carbon oxides: the lower the selectivity, the more carbon oxides are produced. The selectivities presented in the optimization results for the stand-alone operation of the $C P B M R$ are already quite high $(\geq 60 \%)$. Nevertheless, it is examined to what extent it is possible to further increase the selectivity for a given optimal solution by enforcing a lower bound on the selectivity. As a starting point, the intermediate step 1 in 2 is chosen. The yield in $C_{2}$ hydrocarbons at that point lies at roughly $44 \%$ while the selectivity is just above $68.5 \%$.

Apparently, an increase in the selectivity target of one percentage point does not cause the yield to drop by less than that amount. Yield decreases seem to be getting slowly larger when surpassing a selectivity of $75 \%$. Only seven of the eleven decision variables stay at their original value comparing the starting point to the last step of the selectivity target optimization. The most obvious movement here is a shift to an even higher methane to oxygen ratio in the packed-bed as both methane fraction and membrane thickness go up while the oxygen fraction goes down.

Discussion of Results Before proceeding to the next step - the integration of the CPBMR into the membrane reactor network - a short discussion of all results so far is in order.

The performance of the $C P B M R$ reported herein is - with respect to the yield in $C_{2}$ hydrocarbons - better than expected and reaches higher levels than have ever been experimentally found. In order to simulate and optimize the CPBMR successfully, five radial and twelve axial finite elements are required. However, this system seems to be touching its boundaries in the last few optimization studies carried out here. It is possible that with an even larger number of radial finite elements an even better performance with respect to the yield in $C_{2}$ hydrocarbons could be reached. The incorporation of radial effects into the CPBMR model makes a difference and is vital for obtaining more sensible results in comparison to the one-dimensional case. It is exactly this radial influence that makes the simulation and optimization of the CPBMR complicated as it is mainly 
responsible for increasing the number of required variables by a factor of ten.

Overall, the general optimization of the $C P B M R$ has confirmed some of the trends already found in a rough sensitivity analysis that was carried out on the decision variables:

1. There seems to be a general trend towards a thicker membrane. This obviously reduces the heat transfer between shell and tube, but the predominant effect seems to be the reduction of the molar flux of heavier molecules. Oxygen enters the tube through the membrane in the largest quantities, because of the large concentration difference between shell-side and tube-side. Consequently, the thicker the membrane the lower the oxygen flux, and thus, the lower the resulting oxygen concentrations in the reactor tube-side, which apparently ensure the highest possible yields. The oxygen levels found in simulations and optimizations of the CPBMR described above range between roughly zero and $500 \mathrm{~Pa}$. What is interesting to see in this context is that there is - even at the outlet of the $20 \mathrm{~cm}$ long $C P B M R$ - still a positive $C_{2}$ hydrocarbon formation rate. Common perception was that at that point the potential of methane conversion should be exhausted.

2. Inlet temperatures of both shell- and tube-side have dropped below the original $1023.15 \mathrm{~K}$ and the cooling jacket is extracting some $28.5 \mathrm{~W}$ from the reactor in addition to the heat transported away by the shell-side stream while ensuring an almost isothermal temperature level in the tube-side of the $C P B M R$, and thus, allowing for optimal operating conditions along the entire reactor length as shown in Figure 5(c).

3. With respect to the catalytic bed, there seems to be a trend pointing at the minimization of the actual gas phase and covering as much of the packing with catalyst. However, this trend should not be overrated. A sensitivity analysis shows that the actual increase in the yield caused by this trend is comparatively small.

4. Another trend that has reemerged is the increasing dilution of the shell-side gas flow with nitrogen. This can be understood as a further move towards near-isothermal reactor operation as the higher dilution eases the exothermic effects of the reactions. 
5. Lastly, a steady decline in the diameter of both tube and shell is observed. Obviously, this again has two beneficial effects: First of all, the total heat caused by the reaction is smaller. On a smaller diameter the heat transfer through the reactor shell is more effective.

Overall, it appears that the $C_{2}$ hydrocarbon production depends mostly on an optimal temperature control and the presence of a small amount of oxygen in the packed-bed. Economically speaking, however, there is a trade-off between a higher yield through dilution, diameter reduction, and the actual amount of $C_{2}$ hydrocarbons obtained in a reactor. Smaller reactors and higher dilution would require more reactors in total and thus more effort when it comes to the actual product separation. Finally, a few comments need to be made on some numerical issues:

1. After the intermediate step all further attempts to decrease the lower bounds on the temperatures have to be abandoned as the optimization just keeps running into either restoration phase failures or local infeasibilities.

2. The above noted optimization formulations and tasks required, in total, nearly three months to get to the last step.

3. For the last few tasks, the changes made to the variable bounds have to be chosen very carefully and the increases consequentially become ever smaller.

It should, be noted that all the conclusions so far should be handled with care. It is still questionable how accurate the model is and most of all to what extend Stansch's kinetics are in fact applicable in a conventional packed-bed membrane reactor.

There are of course a number of inaccuracies in the implemented reactor model apart from the margins of error of all applied transport and fluid parameter correlations. One issue, in particular, has to be revisited: One reason for the excellent performance of the $C P B M R$ might be a questionable applicability of the kinetics developed by Stansch et al. ${ }^{24}$ Their kinetics have been formulated based on experimental data from the application of the $O C M$ process in a microcatalytic fixed-bed 
reactor. As their reactor does not allow for continuous oxygen injection along the reactor length, the entire amount needs to be fed with methane. This obviously means that the oxygen concentrations at the inlet of the fixed-bed will always be higher than in a PBMR. Consequentially, Stansch et al. claim validity of their kinetics for oxygen partial pressures ranging from $1 \mathrm{kPa}$ to $20 \mathrm{kPa}$. This can lead to some minor trouble in a fixed-bed reactor whenever oxygen is consumed by the reaction mechanism and drops below $1 \mathrm{kPa}$, but it is almost certainly an issue from inlet to outlet in a $P B M R$. In the conventional feeding-mode, no oxygen is being injected to the tube-side of the membrane reactor. The only oxygen in the reactor tube-side arrives there by permeating the membrane from the shell-side. Accordingly, the oxygen partial pressure will always stay at quite low levels. In fact, it has been observed that whenever methane conversion is close to or larger than $50 \%$ in the $C P B M R$ model, the oxygen level at every single collocation position is well below $1 \mathrm{kPa}$ ranging from 0 to $500 \mathrm{~Pa}$. As the parameters of the kinetics were not fitted for this range of partial pressures, it can easily be imagined that this leads to an overestimation (or possibly underestimation) of the reactor performance. Given how a $P B M R$ works, there is however no way to guarantee oxygen levels of more then $1 \mathrm{kPa}$ in the fixed-bed - at least with this kinetic system. A closer look at the formation rates of all components for those low partial pressures of oxygen shows indeed a maximum for the formation of $C_{2}$ hydrocarbons for temperatures above $1000 \mathrm{~K}$, well below $1000 \mathrm{~Pa}$ of oxygen. For details on this behaviour see Figure 6 This, by no means, invalidates the kinetic system, but shows that a thorough experimental investigation is required.

\section{Operation of the Membrane Reactor Network}

This section deals with the simulation and optimization of the membrane reactor network shown in Figure 1. After a brief description of the implementation of the one-dimensional models for the FBR and the PPBMR, this part goes on by presenting some details on how those two and the $C P B M R$ are going integrated into the $M R N$. Lastly, details on the attempted general optimization of the $M R N$ will be presented. In addition, the assumption, that one-dimensional models for both 
$F B R$ and PPBMR suffice, is revisited by comparing their results against two-dimensional models.

Implementation of Models for FBR and PPBMR: The $F B R$ is expected to be considerably shorter than the CPBMR. Hence, only one heating/cooling segment is introduced. Methane and oxygen need to be fed to the reactor at the same inlet. Consequently, the concentration profiles can be expected to be steeper and temperature hot spots could be more of a problem. This basically means that the length of individual finite elements needs to be a lot smaller and that more axial finite elements are required in comparison to the $C P B M R$. Keeping the temperature in the reactor in check is a bit more of a challenge compared to the CPBRM as feed dilution with nitrogen gas of more than $80 \%$ together with a catalyst dilution of one to four was necessary in previous work. ${ }^{33}$ It appears that the heat transfer through the outer shell is even more important in the FBR compared to the $C P B M R$. It is found that especially oxygen disappears quite quickly, when the temperature level gets out of control. Moreover, the axial derivative becomes so large that for longer finite elements negative oxygen values are unavoidable as the collocation is incapable of accurately following that decline. Apart from being unacceptable, the temperature increase is also contradictory to the aim of achieving high yields in $C_{2}$ hydrocarbons. For a feed dilution of $85 \%$, methane conversion climbs to roughly $62.5 \%$, however, selectivity is so low that there is close to no yield in $C_{2}$ products at all. For a $87 \%$ dilution, this is fairly different: Methane conversion is half as high at $33.8 \%$ and the yield in $C_{2}$ around $7.6 \%$. The sudden formation of hot spots needs to be taken into account as this requires a denser discretization. As a starting point, $1 \mathrm{~cm}$ of reactor length will be discretized with 100 axial finite elements each $10^{-4} \mathrm{~m}$ long. The higher oxygen levels in the tube-side of the $P P B M R$ cause the same trouble as in the $F B R$, meaning that yet again a higher number of finite elements is required, which need to be quite short. The PPBMR in the $M R N$ sits right behind the $F B R$. Some additional oxygen and nitrogen is added to the flow leaving the $F B R$ before entering the $P P B M R$, but for now the concentrations of the flow leaving the $F B R$ will simply be reused for the inlet of the tube of the PPBMR. The required dilution with nitrogen found here is obviously quite high. This is, however, not necessarily unexpected. The best yield 
in $C_{2}$ hydrocarbons experimentally reported so far requires a dilution of methane with helium of $98 \%$ while allowing for a yield of $35 \%$ and a selectivity of $54 \%$ in a membrane reactor using a $B i_{1.5} Y_{0.3} \mathrm{Sm}_{0.2} \mathrm{O}_{3-\Delta^{-} \text {-catalyst,. }}{ }^{35}$ Figures 7 and 8 show the concentration profiles for the reaction zones of both reactors at a feed dilution of $87 \%$.

Integration of $F B R, P P B M R$, and $C P B M R$ : For practical reasons, the network has basically only two different feed streams: the first containing methane, the second oxygen. Both gases will be diluted with nitrogen. This means that streams 2, 11, and 14 (see 1) consist of the same molar fractions of oxygen and nitrogen, streams 1, 9, and 6 of the same molar fractions of methane and nitrogen. As a starting point and to get a good match with the previously done simulations of $F B R$ and PPBMR, each stream is diluted to a molar fraction of nitrogen of $87 \%$. Because of recycle stream number 7 from $P P B M R$ shell-side to $C P B M R$, tube-side superficial velocities in both $F B R$ and $P P B M R$ are reduced to $0.4 \mathrm{~m} / \mathrm{s}$ to ensure that the same can stay below or at $1 \mathrm{~m} / \mathrm{s}$ in the $C P B M R$. The heating/cooling temperature in the CPBMR is slightly decreased to $950 \mathrm{~K}$ to prevent possible problems as a consequence of recycle stream no. 7 from the shell-side of the $P P B M R$ to the tube-side of the CPBMR. Similarly, as a further precaution, the shell-side inlet temperature of the PPBMR is decreased to $900 \mathrm{~K}$. Both stream 14 , which is initally set to zero, and recycle stream 12 , which will be activated to just $5 \%$ of its possible flow, can increase the oxygen concentration in the tube-side of the $P P B M R$, and thus, strengthen exothermic reactions. 3 contains the results of the network simulation for the configuration described above.

Table 3: Results of the $M R N$ simulation.

\begin{tabular}{lrrr}
\hline Component & $\begin{array}{r}\text { Yield in } \\
C_{2} \text { Products }\end{array}$ & $\begin{array}{r}\text { Selectivity in } \\
C_{2} \text { Products }\end{array}$ & $\begin{array}{r}\text { Conversion of } \\
\text { Methane }\end{array}$ \\
\hline \hline$F B R$ & 0.047666 & 0.194696 & 0.244823 \\
$P P B M R$ & 0.008562 & 0.142233 & 0.060195 \\
$C P B M R$ & 0.418325 & 0.603931 & 0.692669 \\
\hline$M R N$ & 0.293901 & 0.430539 & 0.682637 \\
\hline
\end{tabular}

This point is obviously far from being an optimal solution as both methane conversion and yield in 
$C_{2}$ hydrocarbons of the network are lower than those for the individual $C P B M R$. Nevertheless, it is a good starting point in order to show that the network model actually works. The CPBMR in the network is probably close to the optimal solution found in the stand-alone optimization, because of the high dilution with nitrogen required by the other two reactors. The reduction of the superficial velocity in the $F B R$ causes the temperature in that particular reactor to drop very quickly, thus, reducing the reaction rates to nearly zero after the first $2 \mathrm{~mm}$ of reactor length. The situation in the $P P B M R$ is quite similar, although the reaction rates do not become completely zero before the reactor end.

General Optimization of the $M R N$ : For the general optimization of the MRN, all geometrical and operational parameters mentioned for the CPBMR can be manipulated. In addition, more or less the same parameters are relevant for the other two reactors. The network itself offers some additional decision variables through the manipulation of recycle streams and the two feed streams. Initial sensitivity analyses at the afore-mentioned starting point show the appearance of numerous (local) infeasibilities brought along by the additional two reactors. Generally speaking, only the improvements described for the CPBMR above led to any improvements in the yield of $C_{2}$ hydrocarbons for the entire network. The sensitivity analysis would imply removing the additional reactors. However, this could simply be because of the excellent performance of the CPBMR at the starting point.

Further Investigation of $\boldsymbol{F B R}$ and PPBMR: The investigation on the CPBMR shows the necessity of its corresponding two-dimensional model. Given the size and complexity of the model for the MRN, only one-dimensional models are first used for the additional reactors. In order to further examine the implications of this simplification, two-dimensional models for both FBR and PPBMR are implemented. Even after a few millimetres of reactor length, the results of one- and two-dimensional models deviate by several percentage points. The simultaneous feeding of oxygen and methane to the catalytic packed-bed leads to the formation of a hot-spot in the reactor center, which cannot be seen in the one-dimensional case. In the case of the FBR, it might be 
possible to tune the behaviour of the $1 \mathrm{D}$ system to the $2 \mathrm{D}$, provided that the temperature can be controlled more effectively. The latter is not possible for the PPBMR. The diffusive flux through the membrane, yet again, necessitates the second dimension. A two-dimensional model for the entire MRN amounts more than half a million variables and cannot be solved in a timely manner using available hardware.

\section{Conclusions and Outlook}

Simulations carried out as part of this work show that using a two-dimensional instead of just a onedimensional model for the $C P B M R$ is necessary and makes quite a difference at higher methane conversion rates, although previously carried out research in this field ${ }^{36}$ suggested the difference maybe rather small. The advantages of the $C P B M R$ in contrast to the $F B R$ have become fairly obvious here. As was proven in the selectivity target investigation, it is possible to ensure both high yields of more than $40 \%$ and selectivities of more than $70 \%$ at the same time. The fairly small influx of oxygen through the membrane prevents side-reactions and helps keep the temperature increase in check at the same time. In addition, the influence of a heating/cooling system on the CPBMR has been tested. The configuration implemented here in combination with the feed dilution allows for almost isothermal temperature profiles in the reactor. These very helpful operating conditions can, however, not be implemented in FBR and PPBMR. The higher oxygen concentrations in the catalytic bed lead to barely controllable temperature spikes causing the oxygen to react fairly quickly and causing low yields in $C_{2}$ hydrocarbons. Further studies show that the radial temperature dependence cannot a priori be neglected in the FBR and is almost certainly an issue in the PPBMR because of the insulating effect of the shell-side.

All the previously drawn conclusions were made under the assumption of applicability for Stansch's kinetics. However, all results obtained for the CPBMR lie in a range for which Stansch et al. do not claim validity for their kinetics. The partial pressure of oxygen simulated in the tube-side of the CPBMR lies well below their lower bound of $1000 \mathrm{~Pa}$ between 0 and 500 . 
Therefore, an important topic for our current research work represents an examination of the applicability of the reaction kinetics applied here. Experiments are on the way so as to test the operating conditions with high yields and selectivities and to distinguish to what extent they are reasonable. For example, Schomäcker et al. ${ }^{37}$ discover that lattice oxygen of a vanadium oxide catalyst plays a greater role at low oxygen pressures. Therefore, the intermediate reduction of the catalyst might influence the selectivity of the reaction mechanism. 


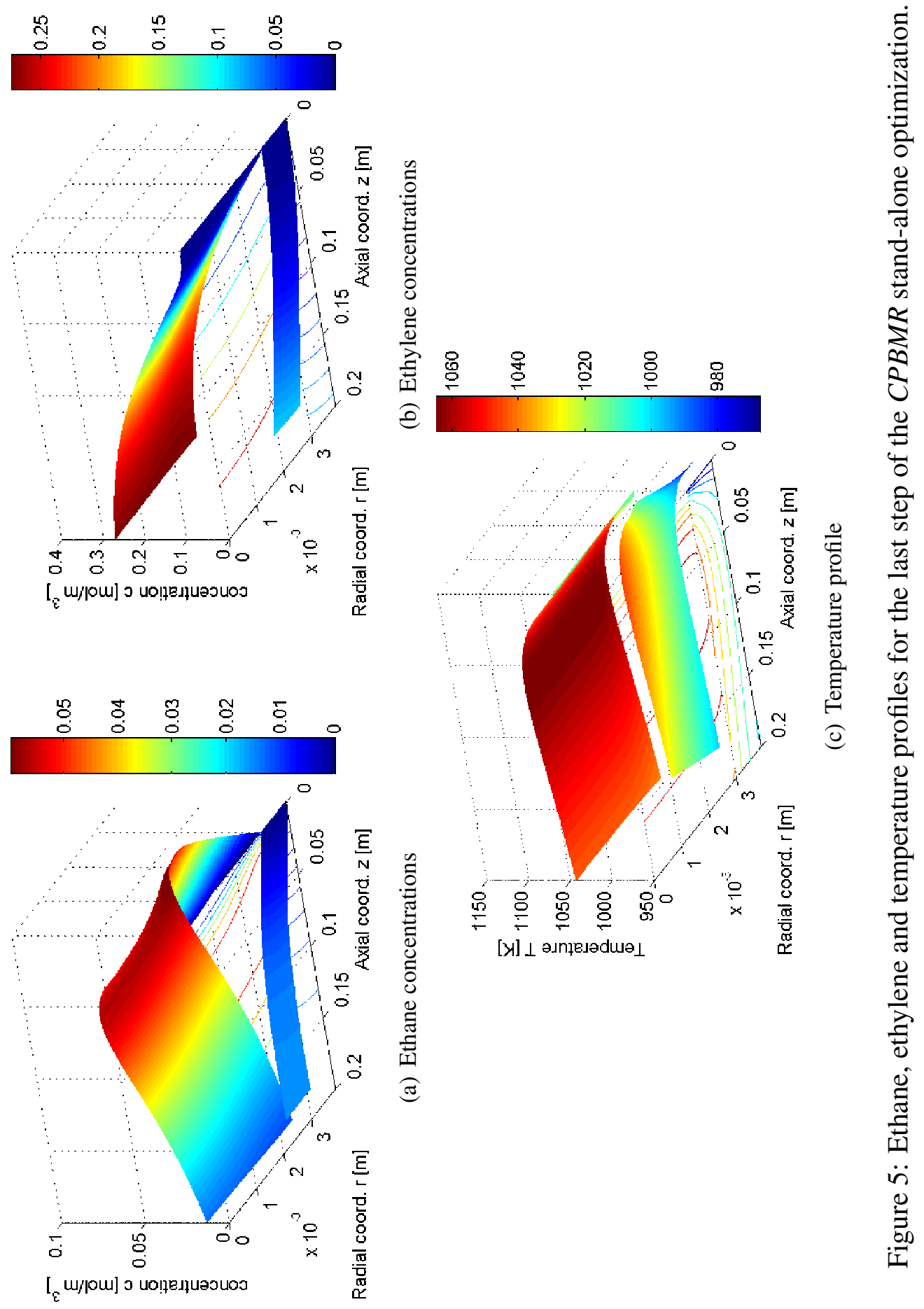




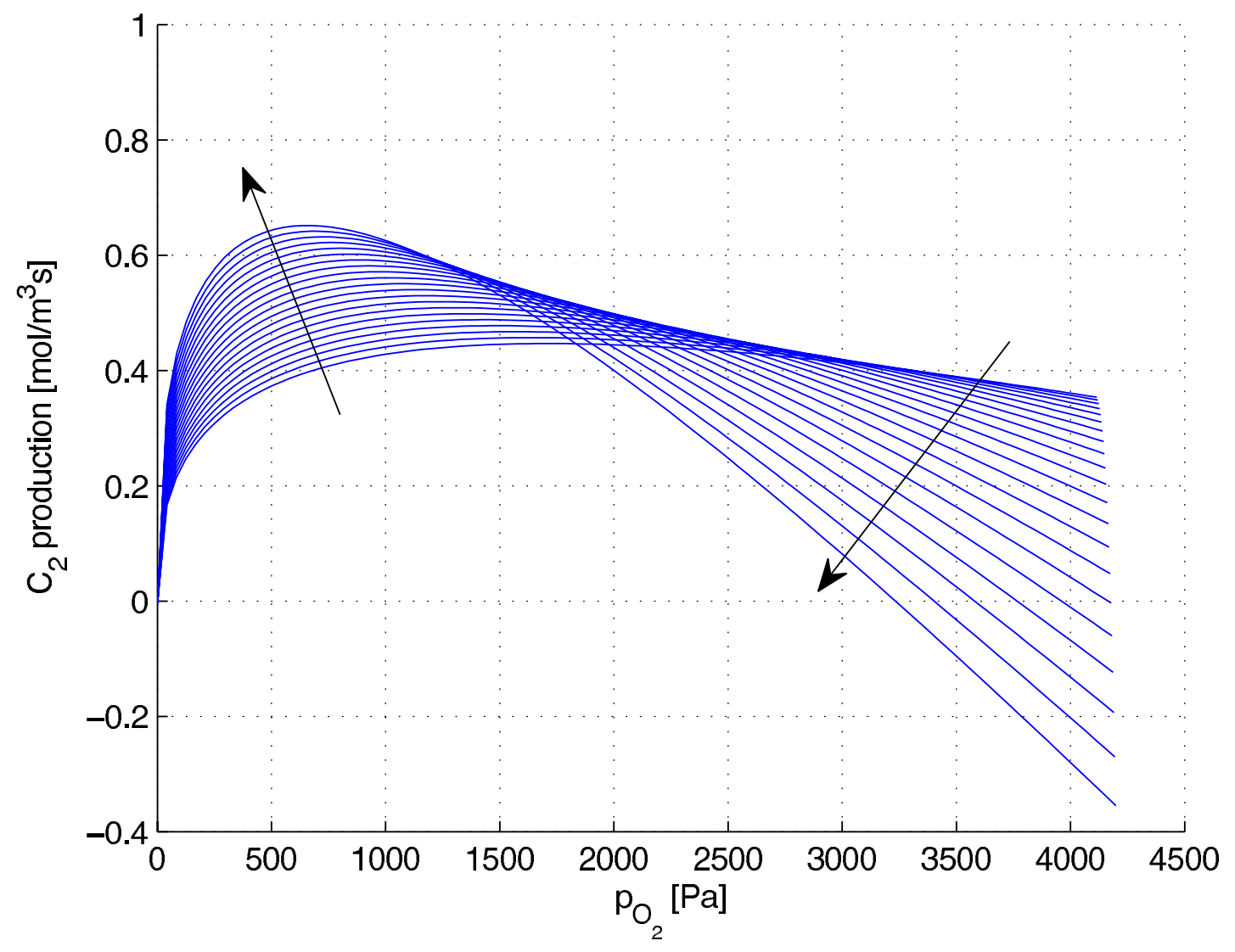

Figure 6: Rate of formation of $C_{2}$ products for various partial pressures of oxygen and different temperature levels. 


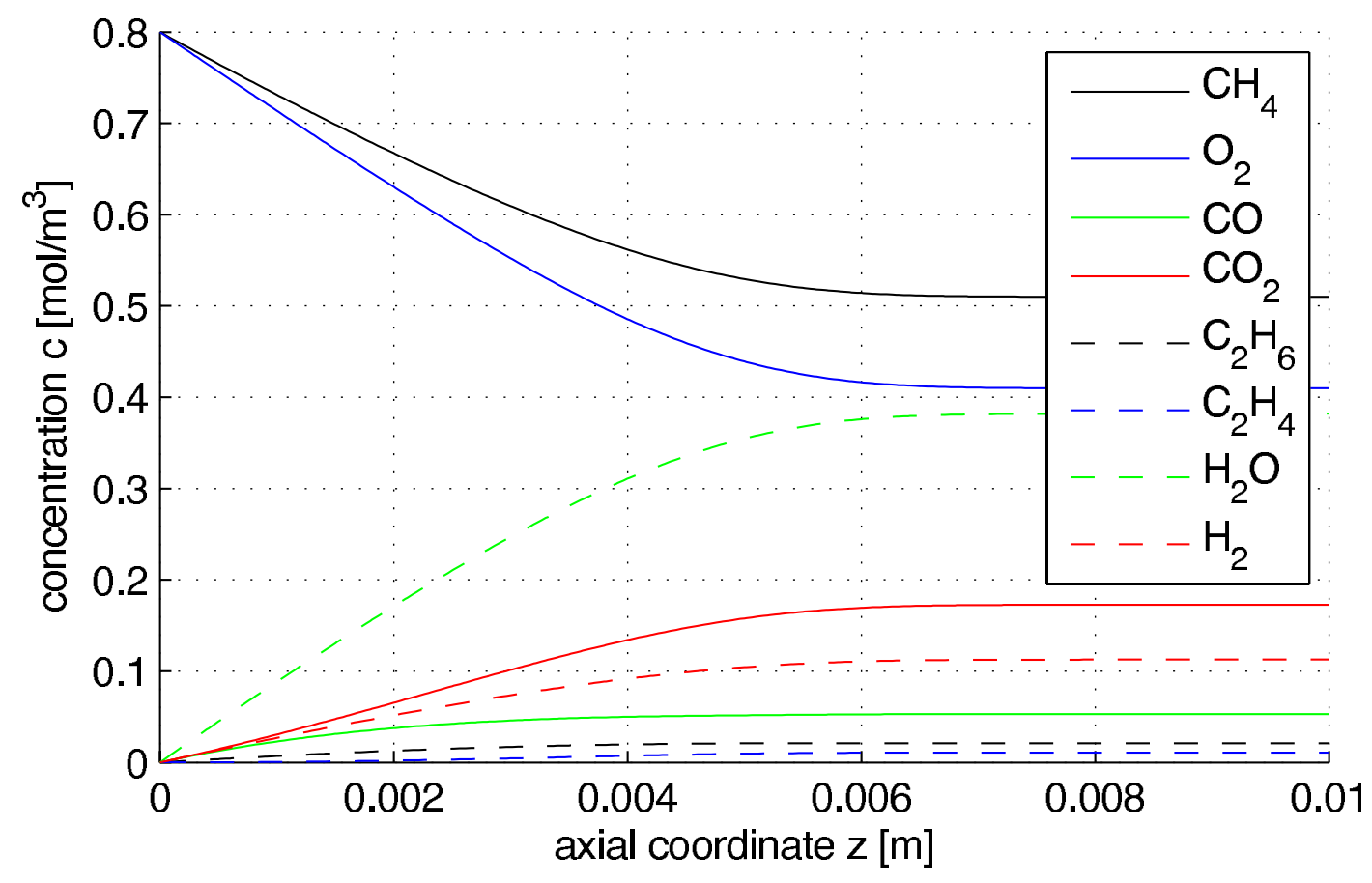

Figure 7: Concentration profiles for the FBR using a feed dilution of $87 \%$.

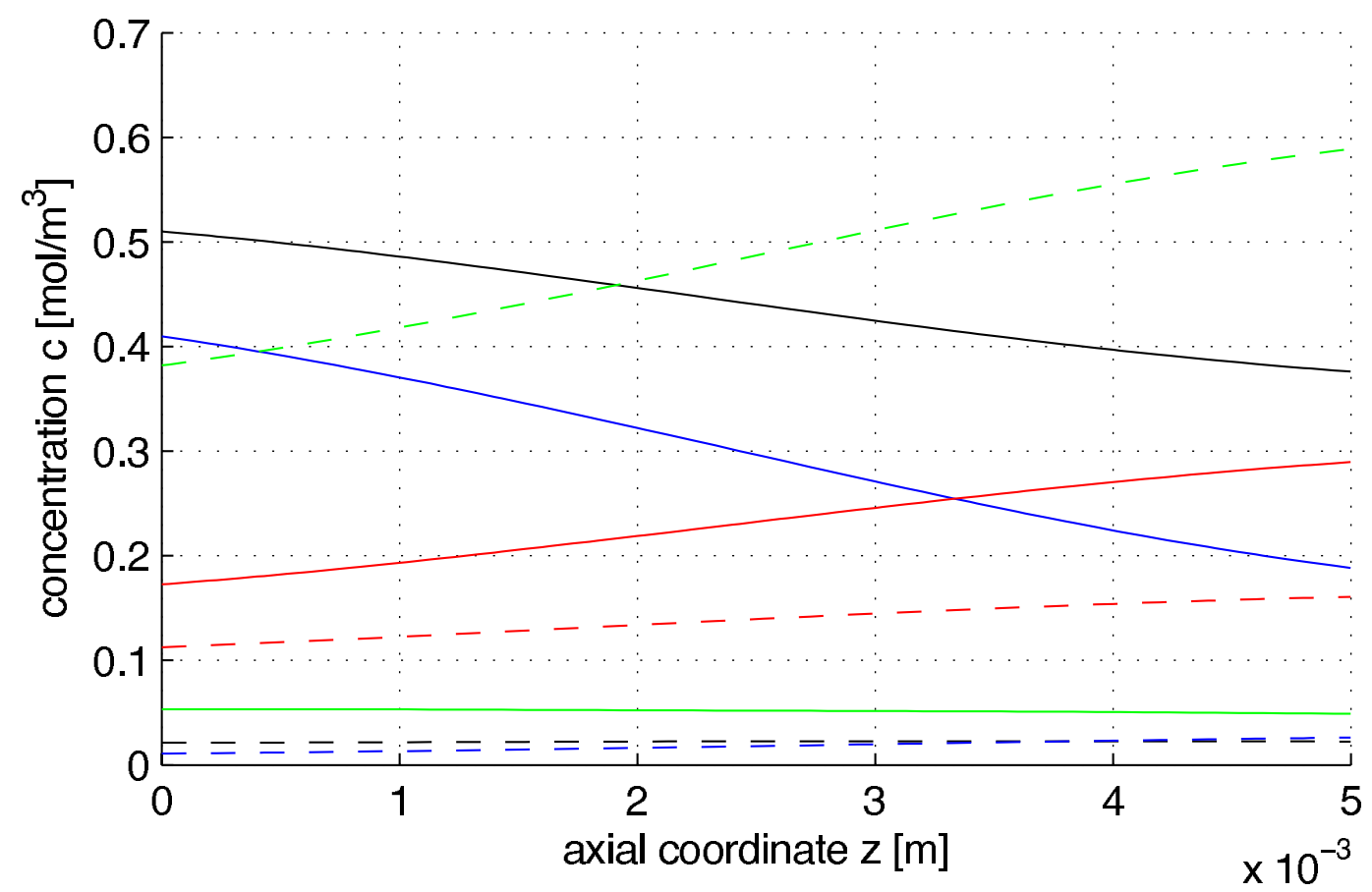

Figure 8: Concentration profiles for the PPBMR tube-side using a feed dilution of $87 \%$. For details on which line symbolizes which component, please refer to 7 . 
Notation

Nomenclature 


\begin{tabular}{|c|c|c|c|}
\hline Symbol & Meaning & Unit & Explanations/Comments \\
\hline$c$ & concentration & $\mathrm{mol} / \mathrm{m}^{3}$ & \\
\hline$c_{p}$ & specific heat capacity & $\mathrm{kJ} / \mathrm{kg} \mathrm{K}$ & \\
\hline$\dot{c r}$ & component rate & $\mathrm{mol} / \mathrm{m}^{3} \mathrm{~s}$ & \\
\hline$\dot{h}$ & enthalpy flux & $\mathrm{W} / \mathrm{m}^{2}$ & area specific enthalpy flow \\
\hline$k$ & heat transfer coefficient & $\mathrm{W} / \mathrm{m}^{2} \mathrm{~K}$ & \\
\hline$\ell$ & Lagrangian polynomial & - & \\
\hline$\dot{q}$ & heat flux & $\mathrm{W} / \mathrm{m}^{2}$ & area specific heat flow \\
\hline$r$ & radius, radial coordinate & $\mathrm{m}$ & \\
\hline$\dot{r r}$ & reaction rate & $\begin{array}{l}\mathrm{mol} / \mathrm{m}^{3} \mathrm{~s} \\
\mathrm{~mol} / \mathrm{g} \mathrm{s}\end{array}$ & $\begin{array}{l}\text { conversion rate of reactions, } \\
\text { differs between gas phase and } \\
\text { surface reactions }\end{array}$ \\
\hline$t$ & time & s & \\
\hline$u_{z}$ & superficial velocity & $\mathrm{m} / \mathrm{s}$ & \\
\hline$z$ & axis, axial coordinate & $\mathrm{m}$ & \\
\hline $\mathscr{D}$ & diffusion coefficient & $\mathrm{m}^{2} / \mathrm{s}$ & \\
\hline $\mathscr{H}$ & Hermite polynomial & - & \\
\hline$\dot{N}$ & molar flow & $\mathrm{mol} / \mathrm{s}$ & \\
\hline$T$ & temperature & $\mathrm{K}$ & \\
\hline$\varphi$ & volume fraction & - & \\
\hline$\lambda$ & thermal conductivity & $\mathrm{W} / \mathrm{m} \mathrm{K}$ & \\
\hline$\rho$ & density & $\mathrm{kg} / \mathrm{m}^{3}$ & \\
\hline$i, j, k$ & index variables & & $\begin{array}{l}\text { walk through components or } \\
\text { reactions }\end{array}$ \\
\hline$r$ & radially & & \\
\hline cat & catalyst & & \\
\hline cool & $\begin{array}{l}\text { variable belongs to heat- } \\
\text { ing/cooling system }\end{array}$ & & \\
\hline diff & diffusion & & \\
\hline $\operatorname{mix}$ & mixture & & \\
\hline shell, $S$ & shell-side & & \\
\hline tot & total & & $\begin{array}{l}\text { e.g. sum or average over all } \\
\text { species }\end{array}$ \\
\hline trans & transfer & & $\begin{array}{l}\text { e.g. heat transfer through a } \\
\text { membrane }\end{array}$ \\
\hline tube, $T$ & tube-side & & \\
\hline & gas & & \\
\hline$O S$ & outer shell & & \\
\hline$C P B M R$ & $\begin{array}{l}\text { coventional packed-bed } \\
\text { membrane reactor }\end{array}$ & & $\begin{array}{l}\text { packed-bed membrane reac- } \\
\text { tor with a conventional feed- } \\
\text { ing policy }\end{array}$ \\
\hline$F B R$ & fixed-bed reactor & & \\
\hline$M R N$ & membrane reactor network & & $\begin{array}{l}\text { network consisting of } F B R \text {, } \\
C P B M R \text {, and } P P B M R\end{array}$ \\
\hline$P B M R$ & $\begin{array}{l}\text { packed-bed membrane reac- } \\
\text { tor }\end{array}$ & & \\
\hline$P P B M R$ & $\begin{array}{l}\text { proposed packed-bed mem- } \\
\text { brane reactor }\end{array}$ & & $\begin{array}{l}\text { membrane reactor with an al- } \\
\text { ternative feeding policy }\end{array}$ \\
\hline
\end{tabular}




\section{Notes and References}

1. Unruh D, Pabst K, Schaub G. Fischer-Tropsch Synfuels from Biomass: Maximizing Carbon Efficiency and Hydrocarbon Yields. Energy Fuels. 2010;24:2634 - 2641.

2. Jašo S, Godini H, Arellano-Garcia H, Omidkhah M, Wozny G. Analysis of attainable reactor performance for the oxidative methane coupling process. Chemical Engineering Science. $2010 ; 65: 6341-6352$.

3. Lafarga D, Santamaría J, Menéndez M. Methan Oxidative Coupling Using Porous Ceramic Membrane Reactors - I. Reactor Development. Chemical Engineering Science. 1994; 49(12):2005 - 2013.

4. Quddus MR, Zhang Y, Ray AK. Multiobjective Optimization of a Porous Ceramic Membrane Reactor for Oxidative Coupling of Methane. Ind Eng Chem Res. 2010;49:6469 - 6481.

5. Ref. 4, p. 6469.

6. Chan PYP. Design and Verification of Catalytic Membrane Reactor for $\mathrm{H}_{2}$ Recovery from $\mathrm{H}_{2} \mathrm{~S}$. Ph.D. thesis, The University of New South West Wales - The School of Chemical Science and Engineering, Sydney, Australia. 2007.

7. Ref. 6, p. 17ff., 46ff.

8. Godini H, Arellano-Garcia H, Omidkhah M, Karimzadeh R, Wozny G. Model-Based Analysis of Reactor Feeding Policies for Methane Oxidative Coupling. Ind Eng Chem Res. 2010; $49: 3544-3552$.

9. Jašo S, Godini H, Arellano-Garcia H, Wozny G. Oxidative Coupling of Methane: Reactor Performance and Operating Conditions. In: 20th European Symposium on Computer Aided Process Engineering - ESCAPE 20, edited by Perucci S, Ferraris GB. 2010; .

10. und Chemieingenieurwesen (GVC) VDIVGV, ed. VDI-Wärmeatlas. Springer-Verlag Berlin Heidelberg, 10th ed. 2006. 
11. Fuller EN, Schettler PD, Giddins JC. A New Method For Prediction of Binary Gas-Phase Diffusion Coefficients. Industrial And Engineering Chemistry. 1966;58(5):18 - 27.

12. Kee RJ, Coltrin ME, Glarborg P. Chemically Reacting Flow. Wiley-Interscience. 2003.

13. Ref. 12, p. 528.

14. Tsotsas E, Schlünder EU. On Axial Dispersion in Packed Beds with Fluid Flow. Chemical Engineering and Processing. 1988;24(1):15 - 31.

15. Tóta Á, Hlushkou D, Tsotsas E, Seidel-Morgenstern A. Packed-bed Membrane Reactors. In: Modeling of Process Intensification, edited by Keil FJ, chap. 5, pp. 99 - 148. WILEY-VCH Verlag GmbH \& Co. KGaA. 2007;

16. Ref. 15, p. 117.

17. Ref. 3, p. 2011.

18. Ref. 10, p. Da 26.

19. Poling BE, Prausnitz JM, O'Connell JP. The Properties of Gases and Liquids. McGraw-Hill. 2001.

20. Bauer R, Schlünder EU. Effective radial thermal conductivity of packing in gas flow. Part I. Convective transport coefficient. Int Chem Eng. 1978;18(2):181 - 188.

21. Bauer R, Schlünder EU. Effective radial thermal conductivity of packing in gas flow. Part II. Thermal conductivity of the packing fraction without gas flow. Int Chem Eng. 1978;18(2):189 $-204$.

22. Specchia V, Baldi G, Sicardi S. Heat Transfer in Packed Bed Reactors With One Phase Flow. Chem Eng Commun. 1980;4:361 - 380.

23. Dixon AG. Wall And Particle-Shape Effects on Heat Transfer in Packed Beds. Chem Eng Comm. 1988;71:217-237. 
24. Stansch Z, Mleczko L, Baerns M. Comprehensive Kinetics of Oxidative Coupling of Methane over the $\mathrm{La}_{2} \mathrm{O}_{3} / \mathrm{CaO}$ Catalyst. Ind Eng Chem Res. 1997;36:2568 - 2579.

25. Biegler LT. Nonlinear Programming - Concepts, Algorithms, and Applications to Chemical Processes. Philadelphia, Pennsylvania: SIAM Society for Industrial and Applied Mathematics \& MOS Mathematical Optimization Society. 2010.

26. Ref. 25 , p. $288 f f$.

27. Finlayson BA. Nonlinear Analysis in Chemical Engineering. McGraw-Hill International Book Company. 1980.

28. Ref. 27 , p. 272.

29. Wächter A, Biegler L. On the implementation of an interior-point filter line-search algorithm for large-scale nonlinear programming. Math Program. 2005;Ser. A.

30. Ref. 25, p. $151 \mathrm{ff}$.

31. Hogg J. HSL Mathematical Software Library. http://www . hs l rl . ac . uk/. 2011.

32. Karypis G, Kumar V. METIS - Graph Partioning, Mesh Partioning, Matrix Reordering. http://people.sc.fsu.edu/\ jburkardt/c\_src/metis/metis. html. 2006.

33. Ref. 2, p.6350, fig. 17.

34. Caro J. Membranreaktoren für die katalytische Oxidation. Chemie Ingenieur Technik. 2006; 78(7):899-912.

35. Ref. 34, p.908.

36. Glöser S. Zweidimensionales Simulationsmodell für einen Membranreaktor zur oxidativen Kopplung von Methan. Technische Universität Berlin - Fachgebiet Anlagen- und Sicherheitstechnik. 2010. 
37. Dinse A, Schomäcker R, Bell AT. The role of lattice oxygen in the oxidative dehydrogenation of ethane on alumina-supported vanadium oxide. Physical Chemistry Chemical Physics. 2009; $11: 6119-6124$.

\section{List of Figures}

1 Flowsheet of the proposed membrane reactor network. Figure redrawn in accordance with. ${ }^{8} \ldots \ldots \ldots \ldots \ldots \ldots \ldots \ldots \ldots \ldots \ldots \ldots \ldots \ldots \ldots$

2 Balance volume for the derivation of the isothermal model for the CPBMR. . . . 6

3 Sketch for the heated or cooled model of the $C P B M R \ldots \ldots$. . . . . . . 7

4 Depiction of the collocating surface function using Hermite and Lagrangian polynomials and the meaning of respective collocation variables. . . . . . . . . . 10

5 Ethane, ethylene and temperature profiles for the last step of the CPBMR stand-

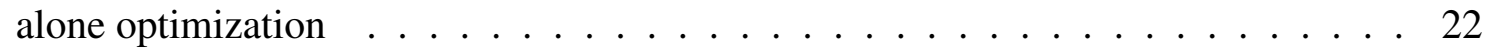

6 Rate of formation of $C_{2}$ products for various partial pressures of oxygen and different temperature levels. . . . . . . . . . . . . . . . . 23

7 Concentration profiles for the FBR using a feed dilution of $87 \% \ldots \ldots 24$

8 Concentration profiles for the PPBMR tube-side using a feed dilution of $87 \%$. For details on which line symbolizes which component, please refer to $7 \ldots$. . . . . . 24

\section{List of Tables}

1 Operational and geometrical parameters of the $C P B M R$ that may be modified within the given bounds. . . . . . . . . . . . . . . . . . . . . . 12

2 Collection of decision variables for three steps in the optimization of the CPBMR and respective performance. $\ldots \ldots \ldots \ldots \ldots$

3 Results of the $M R N$ simulation $\ldots \ldots \ldots \ldots \ldots$ 